\title{
Differences in the Clinical Effects of Angiotensin-Converting Enzyme Inhibitors and Angiotensin Receptor Blockers: A Critical Review of the Evidence
}

\author{
Csaba András Dézsi
}

Published online: 3 January 2014

(C) The Author(s) 2013. This article is published with open access at Springerlink.com

\begin{abstract}
The renin-angiotensin-aldosterone system plays a major role in the pathophysiology of hypertension and closely related cardio- and cerebrovascular events. Although both angiotensin-converting enzyme (ACE) inhibitors and angiotensin receptor antagonists (angiotensin receptor blockers; ARBs) are equally important in the treatment of hypertension, according to the results of recent years, there might be substantial differences in their cardiovascular protective effects, and these differences might be explained by our increasing knowledge of their nonoverlapping mechanisms of action. The number of studies investigating how ACE inhibitors and ARB agents differ will certainly be increasing in the future. ACE inhibitors are the safe therapeutic opportunity for hypertensive patients at high risk, with a cardiological comorbidity.
\end{abstract}

\section{Introduction}

According to the definition of the World Health Organization, hypertension is the leading risk factor of mortality, since diseases associated with high blood pressure, cardiovascular disorders in particular, are responsible for $13 \%$ of total deaths (7.5 million deaths per year) worldwide [1]. Therefore, guidelines of hypertension and cardiological societies emphasize that the antihypertensive treatment should aim at reducing the long-term risks of (cardiovascular) morbidity and mortality [2]. Inhibition of

C. A. Dézsi ( $ه)$

Department of Cardiology, Petz Aladár County Teaching

Hospital, Vasvári P. str. 2-4, Gyor 9024, Hungary

e-mail: dcsa62@gmail.com the renin-angiotensin-aldosterone system (RAAS) is a major therapeutic objective of antihypertensive treatment, since enhanced systemic and/or tissue RAAS activity and high blood pressure are closely related. Among RAAS inhibitors, therapeutic recommendations highlight the importance of angiotensin-converting enzyme (ACE) inhibitors and angiotensin receptor antagonists (angiotensin receptor blockers; ARBs) in the treatment of hypertensive patients [3, 4]. ARBs inhibit the binding of angiotensin II (A-II) to A-II type $1\left(\mathrm{AT}_{1}\right)$ receptors in a competitive manner, while ACE inhibitors reduce RAAS activity by inhibiting the conversion of A-I into A-II [5].

Based on the available evidence, ARBs efficiently reduce blood pressure, decrease left ventricular remodeling after myocardial infarction (MI), inhibit the development of diabetic nephropathy, and reduce the incidence of stroke. These findings have already been formulated in the 2013 recommendation of the European Society of Cardiology/European Society of Hypertension (ESC/ESH) [3]. The American College of Cardiology/American Heart Association (ACC/AHA) guidelines recommend the use of ACE inhibitors in the treatment of heart failure, left ventricular dysfunction, MI, diabetic nephropathy, left ventricular hypertrophy, atherosclerosis of the carotid artery, proteinuria or microalbuminuria, atrial fibrillation, and metabolic syndrome [6].

Although favorable findings are available for both groups, current evidence suggests that the cardio-cerebrovascular protective effects of the two types of medicines might be not identical [7].

The purpose of this summary is to evaluate the potential differences in cardiovascular effects of ACE inhibitors and ARBs, and to provide a global overview of the results published within the last 10 years, focusing on those published in the last 2 years (2011-2013). 
1.1 Initial Doubts that have Emerged in the Last Decade

Based on studies involving patients with diabetic nephropathy, the meta-analysis performed by Strippoli et al. [8] was the first to compare the mortality-reducing efficacy of ACE inhibitors and ARBs when compared with placebo-treated or untreated groups [8]. ACE inhibitors were shown to significantly reduce mortality $(-21 \%$, $p=0.04)$, while ARBs did not influence the risk of mortality $(1 \%, p=0.95)$.

The results of the VALUE (Valsartan Antihypertensive Long-Term Use Evaluation) trial were published in the same year and reported that the incidence of MI was $19 \%$ higher $(p=0.02)$ with valsartan treatment than with amlodipine [9]. This trial provided the first data revealing that the mechanism of ARB action was not entirely clarified and pursued further studies to elucidate this issue.

In 2006, Strauss and Hall [10] published the results of a meta-analysis evaluating the findings of studies performed with 11 different ARBs, with the involvement of more than 55,000 patients. Surprisingly, the incidence of MI was significantly $(8 \%)$ higher $(p=0.03)$ in the ARB group than in the control group (placebo or comparator treatment) despite that blood pressure was reduced with ARBs. Total mortality did not decrease in the ARB group $(+1 \%$, not significant [NS]).

Another analysis, published by Turnbull et al. [11], unequivocally demonstrated that, although ACE inhibitors and ARBs do not differ regarding their effect on stroke risk, a statistically significant difference can be observed with respect to their effect on coronary events.

A few months later, Volpe et al. [12] published an analysis that evaluated the effects of treatments based on ARBs on the risk of MI, cardiovascular death, and allcause death as compared with conventional treatment or placebo. Based on the result of 20 clinical trials, there were no significant differences in the risk of MI between treatment with ARBs versus placebo (odds ratio [OR] 0.944;
$95 \%$ confidence interval [CI] 0.841-1.060) or ACE inhibitors (OR 1.008; $95 \%$ CI 0.926-1.099).

Although the findings of the above publications were criticized and debated worldwide, it seems that the two RAAS inhibitor groups might not be therapeutically equivalent. In 2011, another meta-analysis, by Bangalore et al. [13], was performed in order to objectively and comprehensively clarify the clinical benefits and limits of the ARB group. By analyzing the findings of 37 clinical trials with approximately 150,000 participating patients, they concluded that, although ARB agents do not increase the risks of MI and total mortality (Fig. 1), they do not decrease the risks of infarction and mortality significantly, even when compared with placebo. Nevertheless, ARBs were shown to significantly reduce the risks of stroke, heart failure, and new-onset diabetes mellitus.

\subsection{Effects of Angiotensin-Converting Enzyme (ACE) Inhibitors and Angiotensin Receptor Blockers (ARBs) on Mortality in Hypertensive Patients}

The meta-analysis performed by van Vark et al. [14] included studies published in the past 10 years with hypertensive patients in whom the benefits of RAAS inhibition were expected to develop mainly in connection with blood pressure reduction. Eight studies with less than $66.7 \%$ of the participants diagnosed with hypertension were also excluded. Finally, five trials (including INVEST [International Verapamil SR/Trandolapril Study], ACCOMPLISH [Avoiding Cardiovascular Events in Combination Therapy in Patients Living with Systolic Hypertension], and ONTARGET [The ONgoing Telmisartan Alone and in combination with Ramipril Global Endpoint Trial]) were excluded because RAAS inhibitors were used in both study arms.

Thus, 20 trials met the inclusion criteria for the metaanalysis. In total 158,998 patients were randomized in the RAAS inhibitor $(n=71,401)$ or control $(n=87,597)$ groups. Seven trials used an ACE inhibitor $(n=76,615)$, whereas an ARB was administered in 13 trials
Fig. 1 Effects of ARBs on the various endpoints in placebocontrolled studies [13]. Graphic representation of data. $A R B$ s angiotensin receptor blockers, $N S$ not significant

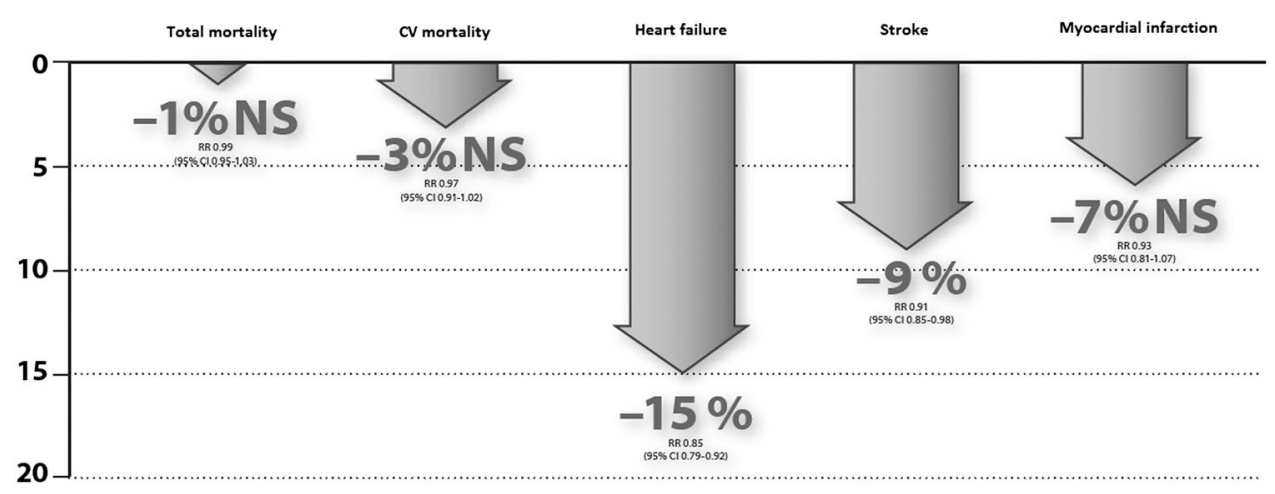


( $n=82,383$ ). According to the definition set by the individual studies, on average, $91 \%$ of the study participants suffered from hypertension.

During the mean follow-up period of 4.3 years in all 20 trials, RAAS inhibitor treatment decreased total mortality in a statistically significant manner, by $5 \%$ (hazard ratio [HR] 0.95; $95 \%$ CI 0.91-1.00; $p=0.032$ ). However, this reduction was entirely associated with the beneficial effect of ACE inhibitors. ACE inhibitors decreased all-cause mortality by a statistically significant $10 \%$ (HR 0.90; $95 \%$ CI $0.84-0.97 ; p=0.004)$. No statistically significant reduction in mortality was observed for ARB treatment (relative risk reduction [RRR] $-1 \%$; HR 0.99; $95 \%$ CI $0.94-1.04 ; p=0.683)$. The difference in the therapeutic effect of ACE inhibitors and ARBs was statistically significant $(p=0.036)$. In patients randomized to receive an ACE inhibitor, the number of cardiovascular deaths decreased by $12 \%$ when compared with the control group (HR 0.88; $95 \%$ CI 0.77-1.00; $p=0.051$ ). In ARB studies, only a reduction by $4 \%$ was observed $(p=0.143)$. In conclusion, this meta-analysis, involving more than 150,000 patients, showed an important difference between the total mortality-reducing effect of ACE inhibitors and the ARBs.

\subsection{Effects of ACE Inhibitors and ARBs on Mortality- Morbidity Endpoints in High-Risk Patients with Preserved Left Ventricular Function}

Another meta-analysis that was presented at a recent session of the AHA (AHA Scientific Session, Dallas, 2012) and subsequently published included trials involving highrisk patients without heart failure (26 trials, $n=108,233$ ) $[15,16]$. This study also evaluated which group of RAAS inhibitors (ARBs or ACE inhibitors) reduced the risk of cardiovascular morbidity/mortality more robustly when compared with placebo.

ACE inhibitors reduced the risk of the primary endpoint composed of three factors (cardiovascular mortality, MI, stroke) in a statistically significant manner, by $14.9 \%$ (OR
$0.83 ; 95 \%$ CI $0.744-0.927 ; p=0.001)$, while this effect was considerably lower, only $7 \%$ (OR $0.92 ; 95 \%$ CI $0.869-0.975 ; p=0.005$ ) for ARBs. In line with the results of previous meta-analyses, ACE inhibitors significantly reduced the risks of total mortality by $8 \%(p=0.008)$, MI by $18 \%(p<0.001)$ and stroke by $20 \%(p<0.004)$, while ARBs did not influence either the risks of total and cardiovascular mortality (NS) or that of MI (NS). In the case of ACE inhibitors, cardiovascular mortality was the only parameter that did not show a significant reduction $(-10 \%, p=0.112)$ (Fig. 2).

Both the analysis above and its implications are belied somewhat by the findings from the ONTARGET study. During the latter, the direct comparison of ramipril (an ACE inhibitor) and telmisartan (an ARB) did not reveal any significant difference in the most relevant cerebral and cardiovascular outcomes. Besides, this result is further tarnished by the relative 'failure' of the TRANSCEND (Telmisartan Randomized Assessment Study in ACE Intolerant Subjects with Cardiovascular Disease) study, which raises a dilemma. In particular, considering that telmisartan has proven similar in its efficacy to placebo, one can only wonder if - in view of the findings from the ONTARGET study-ramipril too would have failed against placebo.

The results available from the ONTARGET and TRANSCEND studies, as well as from the meta-analysis discussed in the foregoing, appear to lead to the following conclusions. First, the benefit of ACE inhibitors is evident in the reduction of cerebral and cardiovascular events in patients with high cardiovascular risk and preserved left ventricular function. Second, although the equivalence between ARBs and ACE inhibitors has been demonstrated, the proof is incomplete.

\subsection{The Use of ARBs in Heart Failure: Contradictions and Doubts}

The rationale for the use of ACE inhibitors in systolic heart failure was based on results of two very important randomized clinical studies (CONSENSUS [Cooperative
Fig. 2 Effects of ACE inhibitors and ARBs on the risks of clinical endpoints in high-risk cardiovascular patients without heart failure $[15,16] . A C E$ angiotensin-converting enzyme, $A R B \mathrm{~s}$ angiotensin receptor blockers, $C V$ cardiovascular, $N S$ not significant

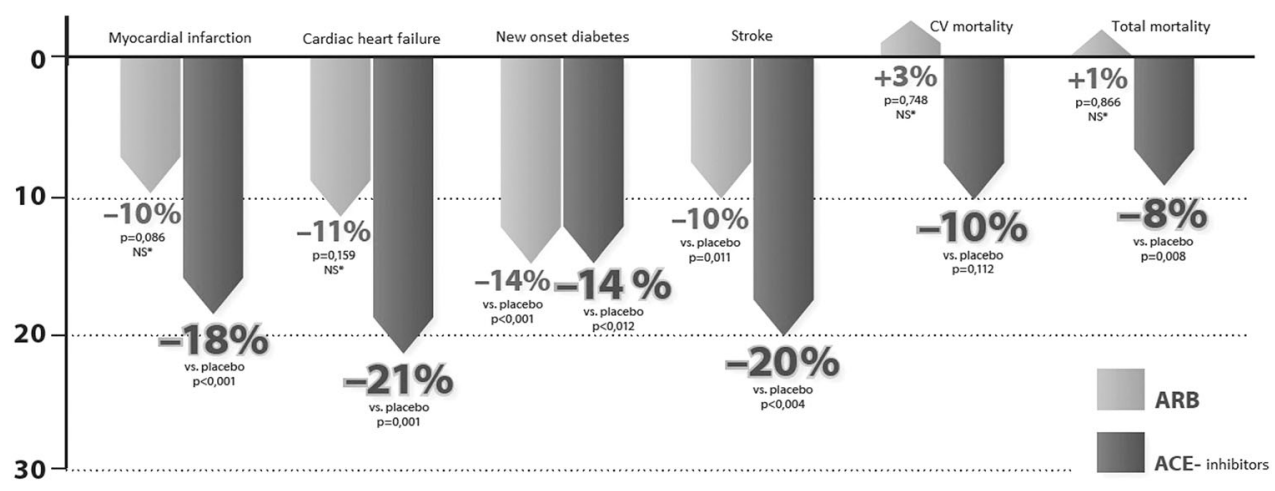


North Scandinavian Enalapril Survival Study], SOLVD [Studies of Left Ventricular Dysfunction]-treatment) [17]. Both studies confirmed that treatment with ACE inhibitors significantly reduces mortality: mortality decreased by $27 \%$ in the CONSENSUS trial and $16 \%$ in the SOLVDtreatment study, while the relative risk of hospitalization for heart failure decreased by $26 \%$ compared with the placebo arm $[18,19]$. The use of ACE inhibitors was further supported by results of a study involving patients with asymptomatic left ventricular dysfunction (SOLVD-prevention) and those of the three randomized, placebo-controlled post-acute MI (AMI) trials involving a large number of patients (SAVE [Survival and Ventricular Enlargement], AIRE [Acute Infarction Ramipril Efficacy], TRACE [Trandolapril Cardiac Evaluation]) [20]. Based on these evidences, the first-line use of ACE inhibitors in the treatment of heart failure is well supported by international recommendations [21].

What could we learn about the evidence for ARBs? The meta-analysis (the Cochrane review) of ARB studies involving 17,900 patients with heart failure and left ventricular dysfunction (ejection fraction $[\mathrm{EF}]<40 \%$ ) and 7,151 patients with heart failure but preserved left ventricular function $(\mathrm{EF}>40 \%)$ was also very informative [22]. In the case of patients with preserved left ventricular function, the pooled findings of two studies (CHARMPreserved [Candesartan Cilexetil in Heart Failure Assessment of Reduction in Mortality and Morbidity] and I-PRESERVE [Irbesartan in Heart Failure with Preserved Systolic Function]) confirmed that ARB treatment did not decrease either total mortality (RR 1.02; $95 \%$ CI $0.93-1.12$ ) or cardiovascular mortality (RR $1.02 ; 95 \%$ CI $0.90-1.14)$ when compared with the placebo group. However, it should be noted that, during the one and only study that evaluated an ACE inhibitor in this patient population (i.e. the PEP-CHF [Perindopril in Elderly People with Chronic Heart Failure] trial), only the rate of hospitalization for worsening heart failure showed a substantial decrease compared with placebo [23, 24]. Seven published clinical studies performed with patients with left ventricular dysfunction reported data on total mortality. The analysis of these studies shows that ARB treatment did not reduce total mortality relative to placebo even in the case of patients with left ventricular dysfunction (RR 0.91; $95 \%$ CI $0.79-1.04)$.

According to the concept of a complete RAAS blockade, the combination of ACE inhibitors and ARBs might have seemed a promising option in the treatment of heart failure. Many clinical studies evaluated the potential benefits of a combination treatment relative to ACE inhibitor monotherapy (e.g. ADEPT [Addition of the AT 1 receptor antagonist eprosartan to ACE inhibitor therapy in chronic heart failure], V-Heft [Vasodilator Heart Failure Trial],
RESOLVD [Randomized Evaluation of Strategies for Left Ventricular Dysfunction], CHARM-Added [Candesartan Cilexetil in Heart Failure Assessment of Reduction in Mortality and Morbidity Added], Val-Heft [The Valsartan Heart Failure Trial]). Seven published clinical studies reported the results on total mortality $(n=8,260)$ and only two $(n=7,558)$ on cardiovascular mortality [22]. According to the findings of the meta-analysis, the two treatment groups (ARB + ACE inhibitor vs. ACE inhibitor monotherapy) did not differ in their effects on total mortality (RR 0.98 ; $95 \%$ CI $0.90-1.06$ ) or cardiovascular mortality (RR 0.93 ; $95 \%$ CI $0.84-1.03$ ). These results suggest that a more complete RAAS blockade is not more beneficial, meaning that, regarding outcomes, the effects of combination therapy and ACE inhibitor monotherapy are comparable. Moreover, combination treatment involves many additional risks of side effects.

We can therefore conclude that when treating heart failure patients, the addition of an ARB to the standard ACE inhibitor treatment does not reduce total mortality, irrespective of the left ventricular function. When treating patients with impaired left ventricular function with a combination of an ACE inhibitor and an ARB, the incidence of hospitalization for heart failure decreased in a significant manner. Thus, the combination of a betablocker and RAAS inhibition achieved by an ACE inhibitor seems to be the basis of the treatment of heart failure patients with systolic left ventricular dysfunction. Despite their well known beneficial effects, ARBs may present an alternative to ACE inhibitors, mainly in cases where an ACE inhibitor is not tolerated [20,21]. As a result of the more selective RAAS inhibition provided by ARBs and due to their better tolerability, the large-scale use of this group in heart failure seems to be reasonable despite the related evidence still being contradictory and not convincing.

\subsection{Effects of ARBs and ACE Inhibitors on the Risk of Myocardial Infarction}

The effect of ARBs on the risk of MI is an important question and has long been debated. The first major, abovementioned meta-analysis (Strauss and Hall [10]) found that ARB treatment paradoxically increased the risk of MI in a significant manner $(+8 \%, p=0.03)$ when compared with the control group (placebo or comparator treatment). Although a recently published meta-analysis refuted the notion that ARBs increase the risk of MI, the results of certain studies may still raise doubts [12]. For instance, in the OPTIMAAL [Optimal Trial in Myocardial Infarction with the Angiotensin II Antagonist Losartan] trial, the incidence of cardiovascular mortality was significantly (by $17 \%)$ higher $(p=0.032)$ in the losartan arm relative to the 
captopril arm during the treatment of patients with acute MI [25]. Total mortality was also, by $13 \%$, higher when compared with the ACE inhibitor treatment arm, although this difference was not significant. In the ONTARGET trial, with the participation of high-risk cardiovascular patients with a high prevalence (approximately $70 \%$ ) of concomitant hypertension, the incidence of fatal and nonfatal MI was $7 \%$ higher in the telmisartan treatment arm (RR 1.07; $95 \%$ CI 0.94-1.22) than in the ramipril treatment arm, although this difference was not significant [26]. In the TRANSCEND trial, high-risk cardiovascular patients intolerant to ACE inhibitors were enrolled, and the ratio of those with a coronary disease reached $75 \%$ [27]. Reductions in the risk of MI were not significant ( $p=0.059)$ with telmisartan relative to placebo treatment.

The potential efficacy of ARBs on MI risk may also play an important role in the treatment of heart failure patients, since heart failure often develops after ischemic heart damage or after an MI. Only two ARB studies enrolling patients with impaired left ventricular function, who did not tolerate ACE inhibitors (SPICE [Statins and ProtonPump Inhibitors on Clopidogrel Antiplatelet Effects], CHARM Alternative) published the incidence of MI in addition to other endpoints. The SPICE trial was characterized by a low number of patients treated with candesartan and a short follow-up period, and found that ARBs did not influence the risks of either mortality or MI [28]. In this respect, the CHARM Alternative study was even more important, since patients with symptomatic heart failure, impaired left ventricular function $(\mathrm{EF}<40 \%)$ and $\mathrm{ACE}$ inhibitor intolerance were enrolled [29]. The mean duration of the follow-up period was 33.7 months. When compared with the placebo group, treatment with candesartan reduced the risk of hospitalization for heart failure (RR 0.73; $95 \%$ CI 0.62-0.85), but it significantly increased the risk of hospitalization for other reasons by $13 \%$ (RR 1.13; $95 \%$ CI 1.01-1.27) and the risk of MI was also higher by $52 \%$ (RR 1.57; $95 \%$ CI 1.10-2.23) when compared with placebo. This may be of critical importance, since MI is present in the medical history of the majority of patients $(>60 \%)$. The increase in the hospitalization for other reasons may be explained by the enhanced risk of MI.

\section{Discussion}

Several clinical studies confirmed the efficacy of ACE inhibitors in the treatment of chronic heart failure (CHF), acute MI and subsequent conditions (post-AMI), as well as in the secondary prevention of coronary artery disease (CAD). Based on the current guidelines for treatment of CHF, post-AMI, and CAD, the ARB can be only substitutional in case of ACE inhibitor intolerance [6, 17, 30, 31].

Indeed, ACE inhibitors and ARBs exhibit largely different inhibitory effects on enhanced RAAS activity (Fig. 3). While ACE inhibitors inhibit the conversion of A-I to A-II, ARBs selectively inhibit the binding of A-II to $\mathrm{AT}_{1}$ receptors. Regarding their pharmacological mechanism of action, ACE inhibitors have one advantage over ARBs, which cannot be neglected: by inhibiting the converting enzyme, they not only reduce the level of A-II, but also inhibit the degradation of bradykinin, hence enhancing the beneficial cardiovascular effects thereof. As is well known, bradykinin inhibits platelet aggregation, reduces
Fig. 3 The double-positive effects of ACE inhibition [32, 33]. $A C E$ angiotensinconverting enzyme, eNOS endothelial nitric oxide synthase, PAI-1 plasminogen activator inhibitor-1, $S M C$ smooth muscle cell, $t-P A$ tissue plasminogen activator

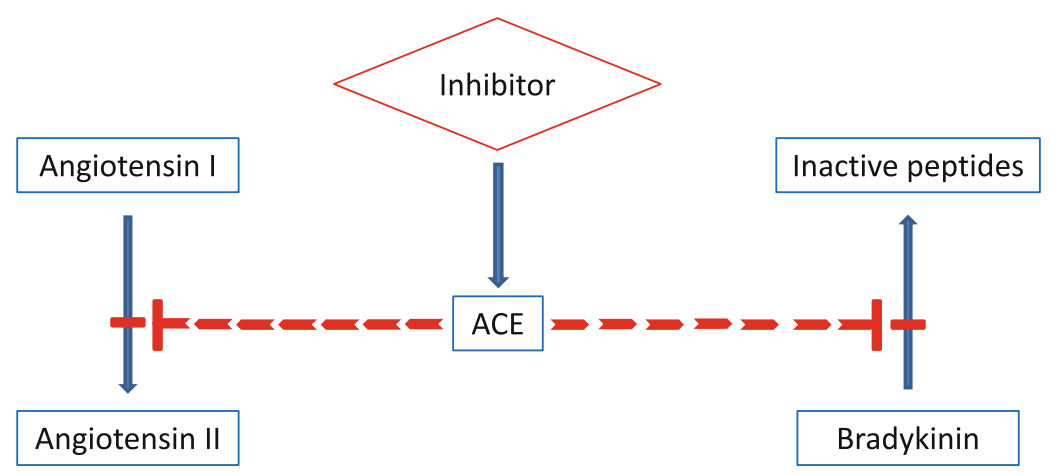

\begin{tabular}{l}
\hline INHIBITION OF ANGIOTENSIN II SYNTHESIS \\
$\downarrow$ Vasoconstriction \\
$\downarrow$ Monocyte adhesion \\
$\downarrow$ Smooth muscle cell proliferation \\
$\downarrow$ PAI-1 levels \& thrombogenesis \\
$\downarrow$ Oxidant release \\
$\downarrow$ Endothelial dysfunction
\end{tabular}

INHIBITION OF BRADYKININ METABOLISM $\uparrow$ Vasodilation

$\uparrow$ Inhibition of monocyte adhesion

$\uparrow$ eNOS expression

$\uparrow$ tPA levels \& fibrinolysis

$\uparrow$ Anti-remodelling

$\uparrow$ Antioxidant effects

Preserved endothelial function 
the level of plasminogen activator inhibitor-1, and also exerts vasodilatory effects by elevating prostacyclin and nitric oxide (NO) levels $[32,33]$. In addition, bradykinin robustly inhibits endothelial apoptosis, thus contribute to enduring endothelial intactness and normal functioning. Consequently, higher bradykinin levels are very likely to reduce the worsening of atherosclerosis [34]. In similar experiments with ARBs, no beneficial effects on endothelial apoptosis could be found [35].

However, research published in recent years has shed light on new, previously unknown characteristics of RAAS activity. Previously, it was thought that $\mathrm{AT}_{2}$-receptor activity is entirely different from that of $\mathrm{AT}_{1}$ receptors, and therefore, $\mathrm{AT}_{1}$-receptor inhibition by ARBs induces favorable changes on $\mathrm{AT}_{2}$ receptors [36-38]. While the beneficial effects of $\mathrm{AT}_{2}$ receptors (cell regeneration, vasodilation, antiproliferative effect, apoptosis, etc.) contribute to tissue reparation after, for example, cerebral ischemia or MI [39], there are data available that, under certain circumstances, $\mathrm{AT}_{2}$-receptor activity can even be harmful by its pro-atherogenic and pro-inflammatory effects, and hence contribute to the rupture of atherosclerotic plaques, leading to acute coronary events [40]. With respect to the fact that the beneficial effects mediated by $\mathrm{AT}_{2}$ receptors are primarily based on experimental data, only clinical data can support or disprove their clinical relevance.

In addition, differences in mechanisms of action not only influence cardiovascular events. A recent study performed with the involvement of post-stroke patients demonstrated that ACE inhibitor treatment is associated with significantly lower risks of pneumonia when compared with the use of control agents, including ARBs [41].

Nevertheless, both agents are characterized by certain advantages and disadvantages. The use of ACE inhibitors is limited by their potential side effects, which might lead to more frequent medication switching relative to ARB treatment. On the other hand, according to accumulating data, the beneficial effect of ARBs on coronary events is not convincing.

\section{Conclusion}

ACE inhibitors are among the most important drug classes of recent decades, since they provided better life expectancy and improved quality of life to millions of patients with hypertension and/or cardiovascular disorders. The efficacy and favorable protective/preventive effects of this drug class were clearly shown by international studies with the participation of thousands of patients.

In the last 15 years, it was hoped that, based on their more specific mechanism of RAAS inhibition, ARBs would offer a therapeutic advantage over ACE inhibitors.
However, the results of completed trials and meta-analyses indicate that those expectations have not been met and ARBs have failed to demonstrate the same or better beneficial effects on clinical endpoints as has already been shown unambiguously by the ACE inhibitors. Accordingly, we should aim at establishing a combination treatment based on ACE inhibitors in patients with cardiovascular comorbidities (CAD, CHF, post-AMI). Rather, ARB agents may be prescribed to patients who do not tolerate ACE inhibitors.

Disclosure The author received no funding for the preparation of this review and has no potential conflicts of interest that might be relevant to the contents of this manuscript.

Open Access This article is distributed under the terms of the Creative Commons Attribution Noncommercial License which permits any noncommercial use, distribution, and reproduction in any medium, provided the original author(s) and the source are credited.

\section{References}

1. Ezzati M, Lopez AD, Rodgers A. Selected major risk factors and global and regional burden of disease. Lancet. 2002;360(9343):1347-60.

2. Kiss I. The Hungarian Society of Hypertension guideline for the management of arterial hypertension. Hypertonia Nephrol. 2009;13(82):81-168.

3. Mancia G, et al. $2013 \mathrm{ESH} / \mathrm{ESC}$ Guidelines for the management of arterial hypertension. J Hypertens. 2013;31:1281-357.

4. National Institute for Health and Clinical Excellence (NICE) clinical guideline 127. Hypertension Clinical management of primary hypertension in adults. http://www.nice.org.uk/guidance/ CG127/NICEGuidance.

5. Atlas SA. The renin-angiotensin-aldosterone system: pathophysiological role and pharmacologic inhibition. J Manag Care Pharm. 2007;13(8) (Suppl S-b):S9-S20.

6. American College of Cardiology/American Heart Association (ACC/AHA). ACC/AHA joint guidelines. http://my.americanheart. org/professional/StatementsGuidelines/ByTopic/TopicsA-C/ACC AHA-Joint-Guidelines_UCM_321694_Article.jsp.

7. Ferrari R, Rosano GM. Not just numbers, but years of science: putting the ACE inhibitor-ARB meta-analyses into context. Int $\mathrm{J}$ Cardiol. 2013;166(2):286-8. doi:10.1016/j.ijcard.2013.01.027.

8. Strippoli GFM, Craig M, Deeks JJ, et al. Effects of angiotensin converting enzyme inhibitors and angiotensin II receptor antagonists on mortality and renal outcomes in diabetic nephropathy: systematic review. BMJ. 2004;329:828-31.

9. Julius $\mathrm{S}$, et al. Outcomes in hypertensive patients at high cardiovascular risk treated with regimens based on valsartan or amlodipine: the VALUE randomised trial. Lancet. 2004;363:2022-31.

10. Strauss MH, Hall AS. Do angiotensin receptor blockers increase the risk of myocardial infarction? Circulation. 2006;114:838-54

11. Turnbull F, Neal B, Pfeffer M, Kostis J, et al. Blood pressuredependent and independent effects of agents that inhibit the renin-angiotensin system Blood Pressure Lowering Treatment Trialists' Collaboration. J Hypertens. 2007;2007(25):951-8.

12. Massimo V, et al. Angiotensin II receptor blockers and myocardial infarction: an updated analysis of randomized clinical trials. J Hypertens. 2009;27(5):941-6. 
13. Bangalore S, Kumar S, Messerli FH. Angiotensin receptor blockers and risk of myocardial infarction: meta-analyses and trial sequential analyses of 147,020 patients from randomised trials. BMJ. 2011;342:d2234. doi:10.1136/bmj.d2234.

14. van Vark LC, Bertrand M, Akkerhuis KM, et al. Angiotensinconverting enzyme inhibitors reduce mortality in hypertension: a meta-analysis of randomized clinical trials of renin-angiotensinaldosterone system inhibitors involving 158998 patients. Eur Heart J. 2012;33:2088-97. doi:10.1093/eurheartj/ehs075.

15. Savarese G, Costanzo P, Cleland JGF, Vassallo E, Rosano G, Perrone-Filardi P. Effects of angiotensin converting enzyme inhibitors and angiotensin receptor blockers on mortality and cardiovascular events in patients without heart failure. A metaanalysis of randomized clinical trials in 108,223 patients. In: Paper presented at: American Heart Association Scientific Session; November 06, 2012; Dallas, TX. Abstract 9641.

16. Savarese G, Constanzo P, Cleland JGF, et al. A meta-analysis reporting effects of angiotensin-converting enzyme inhibitors and angiotensin receptor blockers in patients without heart failure. J Am Coll Cardiol. 2013;61:131-42.

17. McMurray John JV, et al. ESC guidelines for the diagnosis and treatment of acute and chronic heart failure 2012. Eur Heart J. 2012;33:1787-1847.

18. The CONSENSUS Trial Study Group. Effects of enalapril on mortality in severe congestive heart failure. Results of the Cooperative North Scandinavian Enalapril Survival Study (CONSENSUS). N Engl J Med. 1987;316:1429-35.

19. The SOLVD Investigators. Effect of enalapril on survival in patients with reduced left ventricular ejection fractions and congestive heart failure. N Engl J Med. 1991;325:293-302.

20. Flather MD, Yusuf S, Kober L, Pfeffer M, Hall A, Murray G, Torp-Pedersen C, Ball S, Pogue J, Moye L, Braunwald E. Longterm ACE-inhibitor therapy in patients with heart failure or leftventricular dysfunction: a systematic overview of data from individual patients. ACE-Inhibitor Myocardial Infarction Collaborative Group. Lancet. 2000;355:1575-81.

21. Chronic heart failure Management of chronic heart failure in adults in primary and secondary care. This updates and replaces NICE clinical guideline 5. 2010 Augusztus. NICE clinical guideline 108 Developed by the National Collaborating Centre for Acute and Chronic Conditions. http://publications.nice.org. uk/chronic-heart-failure-cg108.

22. Heran BS, Musini VM, Bassett K, Taylor RS, Wright JM. Angiotensin receptor blockers for heart failure (Review). The Cochrane Library, Wylei, no. 4, 2012.

23. Cleland JG, PEP-CHF Investigators, et al. The perindopril in elderly people with chronic heart failure (PEP-CHF) study. Eur Heart J. 2006;27(19):2338-45.

24. Meune $\mathrm{C}$, et al. Meta-analysis of renin-angiotensin-aldosterone blockade for heart failure in presence of preserved left ventricular function. J Cardiovasc Pharmacol Ther. 2011;16(3-4):368-75.

25. Dickstein K. Kjekshus J and the OPTIMAAL Steering Committee: effects of losartan and captopril on mortality and morbidity in high-risk patients after acute myocardial infarction: the OPTIMAAL randomised trial. Lancet. 2002;360:752-60.
26. The ONTARGET Investigators. Telmisartan, ramipril, or both in patients at high risk for vascular events. $\mathrm{N}$ Engl $\mathrm{J}$ Med. 2008;358:1547-59.

27. Yusuf S, TRANSCEND investigators, et al. Eff ects of the angiotensin-receptor blocker telmisartan on cardiovascular events in high-risk patients intolerant to angiotensin-converting enzyme inhibitors: a randomised controlled trial. Lancet. 2008;372:1174-83.

28. Granger CB, et al. Randomized trial of candesartan cilexetil in the treatment of patients with congestive heart failure and a history of intolerance to angiotensin-converting enzyme inhibitors. Am Heart J. 2000;139:609-17.

29. Granger CB, McMurray JJV, Yusuf S, Held P, for the CHARM Investigators and Committees, et al. Effects of candesartan in patients with chronic heart failure and reduced left-ventricular systolic function intolerant to angiotensin-converting-enzyme inhibitors: the CHARM-Alternative trial. Lancet. 2003;362:772-6.

30. Gabriel Steg, Ph, et al. ESC guidelines for the management of acute myocardial infarction in patients presenting with ST-segment elevation. Eur Heart J. 2012;33:2569-619.

31. Montalescot G, et al. ESC guidelines on the management of stable coronary artery disease: the Task Force on the Management of stable coronary artery disease of the European Society of Cardiology. Eur Heart J. 2013;34(38):2949-3003.

32. Campbell DJ, Kladis A, Duncan AM. Effects of converting enzyme inhibitors on angiotensin and bradykinin peptides. Hypertension. 1994;23:439-49.

33. Imre Ungi. The cardiovascular protection effect of angiotensin converting enzyme inhibitors - Is the inhibition of renin-angiotensin system essential only? Cardiol Hungarica. 2012;42:143-6.

34. Ferrari R, Fox K. Insight into the mode of action of ACE inhibition in coronary artery disease: the ultimate 'EUROPA' story. Drugs. 2009;69:265-77.

35. Cangiano E, Cavazza C, Campo G, et al. ACE inhibition modulation of endothelial apoptosis and renewal via endothelial progenitor cells in patients with acute coronary syndromes. Am J Cardiovasc Drugs. 2011;11:189-98.

36. Mehta PK, Griendling KK. Angiotensin II cell signaling: physiological and pathological effects in the cardiovascular system. Am J Physiol Cell Physiol. 2007;292:C82-97.

37. Carey RM. Cardiovascular and renal regulation by the angiotensin type 2 receptor: the AT2 receptor comes of age. Hypertension. 2005;45:840-4.

38. McCarthy CA, Widdop RE, Denton KM, et al. Update on the angiotensin AT2 receptor. Curr Hypertens Rep. 2013;15(1):25-30.

39. Chrysant SG. The role of angiotensin II receptors in stroke protection. Curr Hypertens Rep. 2012;14:202-8.

40. Kim MP, Zhou M, Wahl LM. Angiotensin II increases human monocyte matrix metalloproteinase-1 through the AT2 receptor and prostaglandin E2: implications for atherosclerotic plaque rupture. J Leukoc Biol. 2005;78:195-201.

41. Caldeira D, Alarcao J, Vaz-Carneiro A, Costa J. Risk of pneumonia associated with use of angiotensin converting enzyme inhibitors and angiotensin receptor blockers: systematic review and meta-analysis. BMJ. 2012;345:e4260. 